\title{
Modo de ser historiadora: Cecília Westphalen no campo historiográfico brasileiro da segunda metade do século $\mathrm{XX}^{*}$
}

\author{
Manner of being a historian: Cecília Westphalen in the Brazilian \\ historiography field of the second half of the twentieth century
}

\author{
Daiane Vaiz Machado \\ daiane_vm@yahoo.com.br \\ Doutora em História \\ Universidade Estadual Paulista \\ Avenida Brasil, 746 - Centro \\ 85501-057 - Pato Branco - Paraná \\ Brasil
}

\section{Resumo}

Este estudo investiga algumas faces do percurso intelectual de Cecília Westphalen (19272004). Buscamos interpretar seu modo de ser historiadora nas tensões do campo historiográfico brasileiro da segunda metade do século XX, tempo de delineamento do ofício a partir da instituição universitária. Foi na prática da história econômica e social quantitativa à la Annales, que aprendeu nos deslocamentos historiográficos à École Pratique des Hautes Études, que Westphalen fundamentou seus projetos de pesquisa e diretrizes para o ensino. Para compreendê-los, acenase fundamental a historicização dos seus encontros e desencontros acadêmicos configurados em diferentes espaços de sociabilidade e produção do conhecimento, como a Universidade Federal do Paraná, a Associação dos Professores Universitários de História e a Sociedade Brasileira de Pesquisa Histórica. Para tanto, mobilizamos a produção intelectual de Westphalen, a sua rede de correspondência, anais de eventos e atas de reuniões departamentais.

\section{Palavras-chave}

História intelectual; Historiografia Brasileira; Cecília Westphalen.

\begin{abstract}
This study investigates some facets of the intellectual route of Cecilia Westphalen (19272004). Our intention is to interpret her manner of being a historian in the tensions of Brazilian historiography of the second half of the twentieth century, time of outlining the craft contours as from the university institution. It was by the practice of economic and quantitative social history à la Annales, which she learned on the historiographical displacements to École Pratique des Hautes Études, that Westphalen supported their research projects and guidelines for teaching. To understand them, stand out as fundamental the historicizing of her academic matches and mismatches configured in different places for sociability and production of knowledge, such as the Federal University of Paraná, the Association of University Teachers of History and the Brazilian Society of Historical Research. To do so, we mobilize the intellectual production of Westphalen, her network of correspondence, academic meetings proceedings and minutes of departmental meetings.
\end{abstract}

Keywords

Intellectual history; Brazilian historiography; Cecília Westphalen.

Recebido em: 21/10/2016

Aprovado em: 13/12/2016

* Pesquisa financiada pela Fapesp, processo 2012/17664-6. 
Interrogar-se sobre os modos de ser historiador significa colocar em perspectiva o produto de uma prática específica (CERTEAU 2002). Voltar-se para os procedimentos que perpassam a escrita de um texto histórico compreende inquirir o fazer do historiador atento à sacralização dos objetos, conceitos, metodologias e autores. Suas práticas são situadas na conjuntura historiográfica em que foram executadas e sua produção analisada em diálogo com outros textos e com seus supostos leitores (GUIMARÃES 2005, p. 32; HARTOG 2003). A consideração desta dimensão do ofício se amplia com a indagação individual dos lugares de inserção social, com o mapeamento das redes de pertencimento, a elucidação dos jogos acadêmicos e políticos que convergem para a construção de um nome, "um lugar para si", e a definição de uma posição particular no campo intelectual (SILVA 2002). O historiador também é o sujeito de uma vida singular, o que envolve ter como medida de sua postura historiográfica as suas convicções políticas, suas expectativas de sociedade e considerar que possam existir diferentes formas de "estar no mundo", de atribuir significado às manifestações culturais e conturbações políticas (LORIGA 2011). A partir dessas premissas de partida, exploramos como Cecília Westphalen construiu seu modo de ser historiadora nas tensões no campo historiográfico brasileiro da segunda metade do século XX, período de delineamento do ofício a partir do meio universitário.

\section{UFPR: a construção de um lugar para a pesquisa histórica}

Cecília Westphalen frequentou o terceiro Curso de História e Geografia regulamentado no Brasil. Ele foi criado em 1938, em Curitiba, formando a Faculdade de Filosofia, Ciência e Letras do Paraná, que em 1946 integrou a Universidade do Paraná. ${ }^{1}$ Como o ensino superior recebia poucos subsídios, os alunos deveriam pagá-lo, e assim Westphalen, que em 1946 concluiu a Escola Normal no Instituto de Educação do Paraná, ingressou no Curso de Geografia e História por ser, objetivamente, o mais acessível financeiramente a uma normalista (WILLE 2010). Apesar da escolha ao sabor do possível, essa universidade se tornou seu principal lugar de atuação profissional e de projeção na cena pública.

Diplomada em 1950, sua obra de inserção no mercado editorial, Pequena História do Paraná, ${ }^{2}$ e sua tese de cátedra em História Moderna e Contemporânea, Carlos-Quinto, 1500/1558: seu Império universal, defendida em 1957 (WESTPHALEN 1955), inserem-na em uma historiografia preocupada, sobretudo, em estabelecer os fatos e suas cronologias, preencher lacunas e corrigir pesquisas anteriores, própria à prática dos institutos históricos e geográficos e, ainda, das jovens Faculdades de Filosofia. O desprendimento dessa forma de olhar o passado, de ser historiadora, emerge de seus deslocamentos historiográficos internacionais, ou melhor, do encontro com Fernand Braudel e sua concepção de história, na École Pratique des Hautes Études (EPHE), e da

\footnotetext{
${ }^{1}$ A instituição foi federalizada em 1950.

2 Obra de caráter didático, encomendada para integrar as comemorações dos cem anos de emancipação da $5^{a}$

Comarca de Paranaguá e Curitiba da Província de São Paulo (WESTPHALEN 1953).
} 
aproximação com o grupo de professores que liderará a criação da Associação dos Professores Universitários de História (APUH, hoje ANPUH).

Dos deslocamentos, dois imprimem contornos centrais na ressignificação de sua identidade historiadora, duas experiências chaves no processo cognitivo de aprendizagem da prática da história econômica, com abordagem quantitativa à la Annales, e na arquitetura de sua rede de sociabilidade, ${ }^{3}$ pulsada pelos diálogos historiográficos, apoios para publicação e divulgação de obras, tutelas de estudantes, enfim, relações regidas por trocas intelectuais, institucionais e políticas.

O primeiro localiza-se entre 1958 e 1959 e compreende sua experiência como acadêmica na Universidade de Colônia, Alemanha Ocidental, e um rápido estágio no Centre de Recherche Historique (CRH), na EPHE. ${ }^{4}$ Este deslocamento ocorreu em função da divulgação de sua tese de cátedra e da intenção de colher com Braudel, especialista no século XVI, conselhos para alavancar sua pesquisa.

Com a percepção de que se tornava uma das únicas especialistas brasileiras no assunto, Westphalen rapidamente providenciou a impressão em formato de livro e o enviou para instituições estrangeiras de ensino e pesquisa. A perspicácia quanto à engenharia das relações sociais assegurou-lhe bolsa de estudos para participar dos congressos sobre Carlos $\mathrm{V}$ realizados em Madri e Colônia, onde pôde dar ímpeto à circulação de seu texto. Neste período, diversos centros europeus organizavam eventos por ocasião do IV centenário de morte do imperador.

136 o impresso posto em trânsito analisou a vida de Carlos V (1550-1558). Para situá-lo em uma nomenclatura (o que não significa em uma clausura) historiográfica, diríamos que se trata de uma biografia em que as ações políticas são chaves de compreensão do processo histórico.

Sem apresentar pesquisa original ou erudição, com uma cronologia bem estabelecida e sem lacunas graves, seus críticos internacionais elogiaram a leveza da escrita e o esforço de uma brasileira em conceber um trabalho tão distante das fontes (RICHARD 1958; ROBERT 1958; INFORMATIONS BIBLIOGRAPHIQUES 1958). A falta de manuseio das fontes foi notada nas resenhas francesas: "Muitos estudos de segunda mão figuram no livro", ${ }^{5}$ na apreciação de Jean Richard (1958, p. 223). O que teria desencadeado algumas confusões, como a utilização de textos de autores como citação de contemporâneos do objeto, ou seja, como fontes. Ao submeter sua tese ao julgamento de uma historiografia marcada pelos princípios da crítica metódica, ${ }^{6}$ seu texto não passou de um balanço bem escrito.

\footnotetext{
${ }^{3} \mathrm{~A}$ noção de rede de sociabilidade nos ajuda a refletir sobre os vínculos que Westphalen constituiu nos agrupamentos que fez parte. As redes organizam-se em torno de interesses e afinidades difusas, de ordem intelectual, institucional, política, afetiva. Quando nos aproximamos do microcosmo universitário as eleições podem ocorrer pelo estrito relacionamento profissional (pensando-o como estratégia de pertencimento que pode possibilitar ascensão na carreira), pela cumplicidade de orientações teórico-metodológicas e problemáticas partilhadas, e, o contrário, a oposição ao outro, a hostilidade a outras redes e as particularidades que as unem (SIRINELLI 2003, p. 231-269; 1998, p. 259-279).

${ }^{4} \mathrm{Na}$ Universidade de Colônia Westphalen frequentou os Seminários de Richard Konetzke, estudioso da história social da América colonial espanhola, e de Theodor Schieder, ligado à "história estrutural" (Strukturgeschichte) e ao Grupo de Trabalho de História Social Moderna. A narrativa desta experiência, expressa na correspondência enviada à Altiva Balhana, registra sua insatisfação com o ensino alemão (MACHADO 2016a).

5 "Beaucoup d'études de seconde main y figurent", tradução nossa.

${ }^{6}$ Princípios que, inspirados no historicismo alemão, foram sistematizados por Langlois e Seignobos em fins do
} 
A crítica candente foi, no entanto, a que veio do tête-à-tête com Braudel durante o evento sobre Carlos V na Universidade de Colônia:

Ele deu uma chacoalhada em todo mundo, inclusive em mim, dizendo que a História dos evénements da época de Carlos $V$ estava feita com Brandi, que ninguém o ultrapassará tão cedo e facilmente; que é preciso deixarmos este resumo da história dos acontecimentos para entrarmos na história social, na história de todo dia, história da realidade tal como é, não como parece ser, e por aí a fora (WESTPHALEN 29 nov. 1958).

"Abandonemos esta efêmera história dos eventos, que de um horizonte individualista falseia a história da realidade"!’ esta parece ter sido a direção da intervenção de Braudel. A inovação, que ele ali personificava, era o desafio abraçado pelos Annales desde 1929.

Este breve mapeamento das críticas estrangeiras ao trabalho de Westphalen permite ponderar o lugar concebido ao trato com a crítica metódica naquele espaço de produção e no Brasil. Poder-se-ia ainda associá-lo à primeira indicação de Braudel a Westphalen, quando, enfim, chegou ao $\mathrm{CRH}$ : ir a um lugar repleto de possibilidades para a escrita da história, os Arquivos Nacionais. A experiência com o arquivo era nova para a brasileira. Ensinada em uma estrutura em que predominava a formação do professor para o ensino secundário, ela nunca havia sido "levada a um arquivo durante o curso", pois "a pesquisa, quando exigida, era apenas bibliográfica" (WESTPHALEN 1985, p. 34). Como, afinal, atesta a extensão do balanço bibliográfico de sua tese. ${ }^{8}$

De volta ao Brasil, a missiva escrita a Braudel em 1962 indica-nos como ela conferiu sentido ao seu primeiro deslocamento. Configuram-se centrais em sua narrativa a aproximação com os professores da USP (Eurípedes Simões de Paula, Eduardo D'Oliveira França e Alice Canabrava), a fundação de uma associação nacional de historiadores universitários e a implantação de projetos no Departamento de História (DEHIS) da UFPR: Levantamento de fontes para a história demográfica do Paraná; O comportamento político dos colonos de Santa Felicidade; História agrária do Paraná: formação da estrutura agrária tradicional e mudanças na estrutura agrária; e, Paranaguá e o Atlântico. Este último era o novo empreendimento de Westphalen (WESTPHALEN 1 out. 1962).

O projeto Carlos $V$ cedia espaço à investigação que objetivava, com o Porto de Paranaguá, compreender os alicerces econômicos da sociedade paranaense do século XIX, enfatizando as técnicas da história quantitativa (FURET [1986]; DAUMARD 1959). Desse modo, vemos as implicações da EPHE sob a prática historiográfica de Westphalen.

século XIX. Os quais, segundo Gérard Noiriel, grosso modo, ainda regem a maior parte das regras e hábitos, o modus operandi, dos historiadores e definem os critérios de pertencimento a uma "comunidade histórica" (NOIRIEL 2005).

7 No que tange à ênfase no termo "história da realidade", Braudel considerava que "todas as aventuras individuais se fundem numa realidade, mais complexa, a do social, uma realidade 'entrecruzada', como diz a Sociologia" (BRAUDEL 2009, p. 23).

8 O depoimento de Emília Viotti da Costa, que frequentava o Curso de História e Geografia da USP, corrobora com a imagem descrita por Westphalen: "A pesquisa em fontes primárias não recebia muito estímulo ou orientação. A maioria dos ensaios que escrevíamos eram historiográficos" (COSTA 2002 apud ROIZ 2012, p. 71). 
Trata-se de um processo de transformação de seu vocabulário, a História como ciência social, a dialética da duração, os ciclos econômicos, as séries, a informática, passam a compor sua linguagem no ensino e na pesquisa. Em nível institucional, com o apoio dos colegas, ${ }^{9}$ este novo modo de conceber 0 ofício foi significado na implantação de uma série de medidas de incentivo a modernização do trabalho historiográfico. O ato fundador foi a proposição, por ela, de instituição de um Seminário de História, a partir do qual os docentes estabeleceriam um "sistema de referência para se construir a História do Paraná" (WESTPHALEN et al. 2009, p. 291). Gesto que institucionalizava a busca pela formulação de uma história total, tornando-se a história regional uma estratégia de pesquisa da história praticada no DEHIS. Nesse sentido, forjou-se o "nós" ("sujeito plural que sustenta o discurso")10 desse lugar historiográfico, o fazer história econômica e social regional tornava-se uma intenção coletiva. Esta aparência de unidade não implica um enquadramento estanque, mas indica que havia um claro direcionamento a um estilo de prática historiográfica, a difundida pela historiografia francesa.

Nesse diapasão, iniciaram-se os projetos de pesquisas, que, primeiramente, se voltavam para coleta de fontes, pois a empiria deveria substituir o primado da pesquisa bibliográfica. Para a divulgação parcial dos resultados, criou-se o Boletim do Departamento de História, meio de interlocução com o público acadêmico e não acadêmico e, consequentemente, de afirmação de uma forma de fazer pesquisa.

Os textos publicados nos boletins foram as primeiras incursões no trato de um pesado material de quantificação (WESTPHALEN dez. 1962), eles são vitrines das experimentações em uma nova linguagem historiográfica, dão mostras do penoso processo de aprendizado desta prática e também enfatizam a seriedade do compromisso assumido no Seminário de História.

O impulso para o envolvimento dos alunos nos projetos era dado pela disciplina Introdução à História, que entrou no currículo em 1961 (WESTPHALEN et al. 2009, p. 297). Na disciplina, Westphalen implantou um regime regular de pesquisa de campo na Biblioteca Pública do Paraná e no Arquivo Público do Paraná, concebendo-os como laboratórios da História.

Acompanhando uma década de desenrolar dos conteúdos, vemos uma estrutura disciplinar que tencionava dar ao aluno um panorama geral das possibilidades metodológicas e técnicas do trabalho historiográfico. ${ }^{11} \mathrm{~A}$ confiança de que métodos matemáticos poderiam levar a conhecer o passado com mais sobriedade e precisão, que se depreende desta estrutura, também pautava a grade curricular do Mestrado em História do Brasil.

Com o fortalecimento do par "empiria e metodologia", a forma de organização curricular do Mestrado pode ser percebida como "extensão da graduação",

\footnotetext{
${ }_{9}$ Principalmente Altiva Pilatti Balhana (1928-2009), professora de História da América e Brasil Pinheiro Machado (1907-1997), professor de História do Brasil.

${ }^{10}$ Toda pesquisa individual se situa num conjunto de práticas, essa premissa que ensaia ser implícita, segundo Certeau, está inscrita "numa rede cujos elementos dependem estritamente uns dos outros, e cuja combinação dinâmica forma a história num momento dado" (CERTEAU 2002, p. 71).

${ }^{11}$ O material pode ser encontrado no Acervo do Arquivo Permanente da Universidade Federal do Paraná.
} 
em um enlace de interesses entre projetos de pesquisa docente (com foco na exploração de fontes regionais), ensino na graduação e formação do docente pesquisador no mestrado. Implantado em 1972, o curso surgiu com duas áreas de concentração: História Econômica e História Demográfica, acrescentando, em 1978, a História Social. Pouco depois, em 1981, teve início o Doutorado em História Demográfica.

Para estruturar os currículos, o programa de pós-graduação apostou nos intercâmbios acadêmicos, investiu na vinda de docentes à instituição e no enviou de seus professores a centros de pesquisa no exterior, privilegiando o trajeto à Paris. ${ }^{12}$ Frédéric Mauro, Adeline Daumard, Jacques Bertin e Louis Henry, foram alguns dos docentes franceses que circularam na instituição. Os contatos com estes pesquisadores, como as trocas de cartas evidenciam, ${ }^{13}$ tiveram início, ou se intensificaram, a partir de 1970 quando Westphalen retornou de sua segunda viagem à Paris, onde foi buscar orientação metodológica e apoio técnico para finalizar a fase de cálculos e compor a obra sobre o porto paranaense.

O estreitamento de contatos profissionais na composição de sua rede de sociabilidade internacional foi uma das marcas deste segundo momento de seu deslocamento historiográfico. Isto porque, avaliando a historiografia annalítica, parecia-Ihe que os ares historiográficos eram nuclearmente os mesmos de 1959, ou seja, a concepção de tempo braudeliana permanecia como elemento estruturante das temáticas, a metodologia era a quantitativa e a esfera privilegiada era a econômica e social. Assim, com certo descontentamento, ia aos Seminários de Braudel, Ruggiero Romano e Mauro "só para os contactos como dizem" (WESTPHALEN 21 abr. 1970). A sagacidade de Westphalen desnuda princípios implícitos das engrenagens do microcosmo acadêmico, onde: aprender é importante, mas construir redes de contato, abrindo portas para trocas futuras, também!

O descobrimento do novo, para ela, esteve no acaso do encontro com Bertin no Laboratoire de Graphique (WESTPHALEN 24 jun. 1970), quando se interessou pelo tratamento gráfico da informação a partir dos princípios da semiologia gráfica (BERTIN 1986); e na descompromissada frequência ao Seminário de Henry sobre Demografia Histórica (WESTPHALEN 7 abr. 1970), onde aprendeu a técnica de reconstituição de famílias (HENRY 1977).

Estes dois pesquisadores tornaram-se referenciais nos trabalhos desenvolvidos no Mestrado e Westphalen interpreta um papel importante na circulação de suas produções. Atuando como agente de interlocução de modos de fazer história, ela os trouxe ao Brasil, solicitou estágios e orientação para seus alunos, elaborou projetos editoriais de tradução de suas lições. O engajamento nestes empreendimentos de circulação do conhecimento pode ser alocado ao esforço de construção identitária do Programa de PósGraduação em História, pois ao passo que oferecia metodologia e ferramentas

\footnotetext{
12 Destacamos: Carlos Roberto Antunes dos Santos, Sérgio Odilon Nadalin, Márcia Graf, Jayme Antônio Cardoso, Jair Mequelusse e Ana Maria Burmester, que seguiu para a parte francesa do Canadá.

${ }_{13}$ As cartas compõe, principalmente, o acervo da Coleção Cecília Westphalen, depositado no Arquivo Público do Paraná.
} 
para o público brasileiro, identificava estes autores às disciplinas e projetos desenvolvidos na instituição. ${ }^{14}$

A identidade referida acima se pautava no estabelecimento de uma escola de formação de docentes-pesquisadores em história econômica e demográfica com abordagem quantitativa e tratamento informático. O slogan persuasivo de Westphalen "pas de chiffres, pas d'histoire", era a orientação medular para a produção das dissertações (MACHADO 2016b). Estas foram volumosas e se espalharam entre os séculos XVII e meados do XX, priorizando temas como "Estruturas Agrárias, Campos Gerais, Povoamento do Paraná, Imigrações e Imigrantes, Comércio e Transportes" (MARCHI 1995, p. 40-41).

Este quadro manteve relativa estabilidade até a década de 1980, quando já se consolidavam visíveis frentes de "oposição à Profa. Cecília". A leitura de autores como Michel Foucault, Edward Thompson e Eric Hobsbawn, que começavam a ter maior circulação na historiografia brasileira (RAMOS 2015), também passavam a oxigenar este lugar de produção (MARCHI et al., set. 1992/ago. 1993, p. 137). A despeito desta oxigenação, solidária do ímpeto à pesquisa histórica dinamizado a partir de 1959, foram décadas de relativo destaque do núcleo paranaense, ou, ao menos, de projeção de alguns de seus quadros em representativos lugares de produção do conhecimento, como as sociedades científicas (tópico que estudaremos a seguir). Colocação significativa se ponderarmos a polarização da produção historiográfica em torno do eixo editorial Rio-São Paulo.

\section{ANPUH: lugar de encontros e desencontros}

Em 25 de maio de 1965, Westphalen fez uma pausa nas atividades cotidianas para refletir, a convite da carta de Amaral Lapa, sobre o "falecimento" da APUH. Lapa, então professor na Faculdade de Filosofia de Marília, onde a associação deu seus primeiros suspiros no encontro de 1961, relatava a inércia do Presidente Eremildo Vianna e a não realização do III Simpósio, previsto para 1963 em Fortaleza, e assim, com o peso de ter sido ele o autor da moção fundadora, pedia para que Westphalen se posicionasse ao seu lado na tentativa de impedir o iminente esfacelamento da associação (LAPA 11 mai. 1965; WESTPHALEN 25 mai. 1965).

Apesar de ter sido proposta como medida para suprir o isolamento dos professores universitário de História, a troca de cartas indica que os encontros de 1961 (Marília) e 1962 (Curitiba) não foram suficientes para sedimentar uma consciência associativa. O terceiro simpósio acabou acontecendo em Franca, em 1965, como reorganização de um evento local. Não obstante as circunstâncias, renascia ali a associação de historiadores. Westphalen, eleita $1^{\text {a }}$ Tesoureira, junto com Eurípedes Simões de Paula, Presidente, e Alice Canabrava, ora como

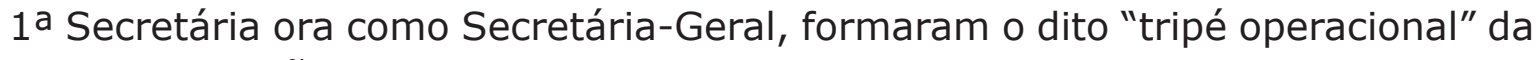
Diretoria (SIMÕES DE PAULA 1973, p. 8).

\footnotetext{
${ }_{14} \mathrm{O}$ processo de seleção de uma tradução é uma das operações sociais relacionadas à circulação internacional das ideias. Como objeto de uma seleção é cabível ponderar a razão do interesse em determinadas publicações (BOURDIEU 2002).
} 
Esta alusão aos encalços dos primeiros anos de existência da associação mostra quão incipiente era o meio historiográfico universitário e como o processo de integração profissional foi lento e trabalhoso. Isto diz muito do lugar da pesquisa naquele momento, um lugar a ser instituído entre os docentes universitários. Ela também nos serve para localizar a presença de Westphalen como agente construtor deste lugar.

A APUH tornou-se um lugar de divulgação de temas de pesquisa, fontes, metodologias, técnicas de análise e debates teóricos. Nesse espaço, Westphalen divulgava os avanços que empreendia com os projetos desenvolvidos na UFPR: imigração e formação populacional; flutuações econômicas no Porto de Paranaguá (servindo-se largamente das teorias dos ciclos econômicos (Juglar, Kondratieff) e de análise estatísticas); formação histórica de Paranaguá; economia do Paraná Tradicional; levantamento de arquivos; técnicas didáticas. Também ministrou cursos $^{15}$ e presidiu mesas-redondas. ${ }^{16}$ As proposições dos simpósios também facilitavam a participação de Westphalen e do grupo da UFPR, na medida em que, pelo menos até 1977 , havia predomínio de temas comumente classificados como pertencentes ao campo da história econômica e social, ${ }^{17}$ sugerindo, assim, a aceitabilidade destes domínios na historiografia brasileira.

A historiadora conquistou uma posição de destaque na associação. Da fundação, em 1961, até o IX Simpósio Nacional, em 1977, exercia cargos na Diretoria e gozava de reconhecimento administrativo e intelectual. Após esse ano, ela não mais circulou nos simpósios.

A Assembleia Geral Ordinária do IX Simpósio foi uma das mais "crispantes" (SIMÕES DE PAULA 1979, p. 13-32). Entre os episódios que levaram a tal definição, nos deteremos em dois: participação de professores secundários e estudantes como comunicadores nas sessões de estudos e repúdio aos Estudos Sociais.

A sigla APUH ou ANPUH (a partir de 1971) impunha delimitações de ordem hierárquica; era uma instituição para agregar professores universitários de História. No decurso dos anos, ela começou a incentivar a participação de estudantes e professores secundários, mas na condição de observadores. Em 1977, o número de estudantes já era superior ao dos docentes. O momento era de ressurgimento dos estudantes como força política frente ao governo militar. $\mathrm{Na}$ esteira do reavivamento do ativismo político, os professores começavam a se articular em Associações Docentes, e a USP foi a primeira (MOTTA 2014, p. 330333). Quanto aos professores secundários, havia o acirramento do "problema" dos Estudos Sociais.

Professores de oposição eram localizados entre a USP e a UNICAMP e desde 1973 alguns nomes passaram a crescer como voz opinativa na ANPUH. Tomava identidade uma célula de pesquisadores que tinha interesse em se

\footnotetext{
${ }_{15}$ A Crise na Civilização Ocidental no VIII Simpósio, em 1975.

16 No IX Simpósio, em 1977, Westphalen coordenou a mesa A História no Currículo dos Cursos de Graduação das Faculdades de Filosofia, e foi debatedora na mesa Os Cursos de Pós-Graduação em História, sob a coordenação de Canabrava.

17 Curitiba, 1962 - A propriedade e o uso da terra; Franca, 1965 - Artesanato, manufatura e indústria; Porto Alegre, 1967 - Colonização e Migração; Campinas, 1969 - Portos, Rotas e Comércio; Goiânia, 1971 - Trabalho livre e trabalho escravo; Belo-Horizonte, 1973 - A cidade e a história; Aracaju, 1975 - A propriedade rural; Florianópolis, 1977 - O homem e a técnica.
} 
manifestar contrário à política militar. Ora, parecia inteligente dar voz aos estudantes e professores secundários e assim congregar forças. Neste cenário, Fernando Novais (USP) propôs alterar o estatuto da instituição para que eles assumissem um papel ativo nas sessões, salvo o direito de voto na Assembléia Geral. Westphalen se opôs alegando desobediência ao estatuto vigente, pois, para uma alteração deste porte deveria ser organizada uma assembléia especial convocada com antecedência. Formaram-se, então, duas chapas: "proposta Novais" e "proposta Cecília" (WESTPHALEN 29 ago. 1977). Foram 73 votos a favor da alteração no estatuto, 14 contra e 5 abstenções.

A votação colocou em questionamento os objetivos e o alcance da associação para fora do meio universitário. Para Westphalen, apressadamente a ANPUH se descaracterizava, pois estudantes na condição de aprendizes pouco conseguiriam levar às sessões e a cultura da pesquisa não era regra entre os professores secundários.

De todo modo, sobressai-se a atitude de democratização da ANPUH com a proposta de alteração de seus estatutos justamente no período em que o país vivia "o apogeu da crença na 'sociedade civil'" (NAPOLITANO 2014, p. 262). Essa contenda, somada às moções de repúdio à censura (MOÇÃO No 5 1979, p. 117), denotam o engajamento de grande parte dos associados com o seu presente. Engajamento localizável na história da associação somente em 1977, pois antes predominou o silêncio.

$\mathrm{Na}$ esteira do ambiente contestatório, promoveu-se uma mesa-redonda 142 sobre Estudos Sociais. ${ }^{18}$ Foi a primeira vez que o tema entrou na programação oficial. O repúdio à Lei no 5.692/71 e suas emendas teve um número expressivo de adeptos e houve consenso de que as opiniões ali expressas deveriam ressoar nas páginas da imprensa (MOÇÃo No 7 1979, p. 121). Westphalen, que via na disciplina a possibilidade de integrar as Ciências Sociais que tinham como objeto comum o homem em sociedade e trabalhava em projeto de implantação nas escolas de Curitiba, novamente saiu derrotada (WESTPHALEN et al. 1976; 1977; VIANA 2015).

Westphalen ocupou diversos cargos de comando, seja dentro da universidade, seja no governo estadual ou federal. Naquele ano, ela era Diretora do Setor de Ciências Humanas, Letras e Artes da UFPR e Conselheira do Conselho Federal da Cultura, por nomeação do general Geisel. É possível afirmar que a historiadora tenha alcançado esses postos por suas relações de certa cordialidade com o regime político à época, mas no que se refere aos debates sobre a disciplina na ANPUH ela alegava que seus colegas desconheciam os meandros da legislação e suas críticas eram de ordem ideológica. O debate sobre Estudos Sociais teria sido "quase apenas monólogo da esquerda em favor das lutas democráticas" (WESTPHALEN 9 ago. 1977).

A historiadora relacionava a esquerda ao marxismo e o marxismo a uma ingênua ideia de revolução. Essa percepção, que preza pelo equilíbrio e não 
pela ruptura, estava em consonância com a história que aprendeu com Braudel. Segundo François Dosse (2003), um de seus mais contundentes críticos, a sua concepção estrutural ao constranger o homem minorava seu papel como força coletiva. Em alguma medida, a visão de mundo de Westphalen estava pautada na filiação intelectual que fizera.

O Simpósio de 1977 é um marco no percurso intelectual de Westphalen, porque é o marco final de sua circulação na ANPUH, até então seu principal espaço nacional de comunicação do conhecimento.

\section{Um novo lugar: a SBPH}

Westphalen não foi a única voz dissonante em 1977, mesmo que silenciosamente os descontentamentos existiram e se tornaram explícitos na figura de Maria Beatriz Nizza da Silva (1938-). Foi dela a proposição de trabalho conjunto para criar outra associação para contrabalançar a ANPUH:

[...] pensei na criação de uma Associação Brasileira de Historiadores. Vocês lembram do que se passou em Florianópolis. Se não me desliguei da ANPUH foi apenas por consideração para com o Prof. Eurípedes [...] acho que chegou a hora de criarmos uma nova Associação que de modo nenhum implique a relação com alunos e com professores secundários, a menos que estes sejam historiadores, isto é, tenham pesquisa histórica original publicada em tese, artigo ou livro. Vocês reparem: a ANPUH marginaliza uma série de historiadores que não são professores universitários. Basta lembrar aqui em São Paulo os historiógrafos do Instituto de Estudos Brasileiros ou do Museu Paulista; e no Rio então muitos exemplos há. Por outro lado marginaliza jovens pesquisadores com teses de Mestrado ou de Doutorado que ainda não estão inseridos numa Universidade (NIZZA DA SILVA 8 mar. 1978).

O ímpeto de Nizza da Silva se intensificou após a sua nomeação como Titular de Teoria e Metodologia da História da USP, em 1980, de cujo concurso Westphalen foi da comissão julgadora. ${ }^{19}$ A ANPUH é um dos observatórios da construção do laço acadêmico entre elas, nos simpósios elas se encontravam constantemente. Nizza da Silva também circulou pelo Programa de PósGraduação da UFPR, a partir de 1974 e em diferentes anos, ela ministrou disciplinas sobre história social. Poderíamos falar de uma empatia pela similaridade de seus perfis: mulheres operosas, líderes austeras, com boa rede de sociabilidade nacional e internacional.

A carta convite que Nizza da Silva enviou à Westphalen, extensiva à Balhana, sugeria uma estratégia de agrupamento: convocar os que se sentiam marginalizados pela ANPUH, desde que fossem ativos na produção científica. Entre

\footnotetext{
19 Nizza da Silva percorreu um caminho interdisciplinar em sua formação intelectual, ela se licenciou em Ciências Históricas e Filosóficas pela Faculdade de Letras da Universidade de Lisboa (1961), na USP defendeu tese de doutorado em Filosofia (1967) estudando a metodologia da história do pensamento do filósofo português Silvestre Pinheiro Ferreira (1769-1848); direcionando-se à disciplina História e à história da cultura brasileira no Rio de Janeiro colonial, defendeu sua tese de livre-docência em Teoria da História na USP (1973), quando mobilizou referenciais da linguística, da antropologia, da sociologia da cultura, da filosofia e da história. O livro Teoria da História, antologia que organizou em 1976, traz textos que discutem problemas teóricos acerca da prática historiográfica em tempos em que esta questão era de segunda ordem e marca muito das suas escolhas na composição de sua produção intelectual.
} 
eles, os pesquisadores que integravam os Institutos Históricos e Geográficos, que eram associados à prática amadora da História. ${ }^{20}$ Reserva, até bem pouco, partilhada por Westphalen. A flexibilização na postura relaciona-se à criação de seu perfil combativo, e a aposta seria em novas alianças para "retomar" o espaço que se julgava encurtado, a partir de 1977 (WESTPHALEN [ago] 1980).

Aos interessados em filiar-se como sócios-efetivos, a Sociedade Brasileira de Pesquisa Histórica (SBPH) colocava-se como acolhedora de diferentes correntes teórico-metodológicas, mas estabelecia uma fronteira distintiva ao rejeitar "manifestações de caráter político ou religioso" (WESTPHALEN 11 nov. 1980; ATA 11 de agosto de 1981). Uma alusão clara ao ocorrido na ANPUH.

Com a imagem de que a politização do discurso acadêmico que a ANPUH promovia prejudicava os resultados científicos da pesquisa, veiculou-se que esta havia se tornado um grande sindicato de pouco diálogo acadêmico. ${ }^{21} \mathrm{Em}$ contrapartida, era possível acusar a SBPH de ser uma sociedade "conservadora/ reacionária", e, mesmo, negacionista de sua responsabilidade ética. Estas figuras de oposição, caricaturais e pouco explicativas, é certo, foram, no entanto, funcionais à época, como se observa na troca de correspondência de Westphalen com os sócios. Na formação destes dois grupos há um ideal de condução da disciplina, uma disputa disciplinar, pouco verbalizada, entre a formação de um perfil de historiador engajado no debate público e um tipo "unicamente" devoto ao "desenvolvimento da pesquisa histórica no Brasil" (WESTPHALEN 11 nov. 1980), em uma acepção de que intervir não seria competência de quem faz ciência.

Cabe referir que a criação de outra sociedade não soava unanimemente como postura de afronta e oposição disciplinar, mas sim como caminho natural de um campo em idade madura. Ou seja, há de se ter cautela com a generalização para todos os sócios dos combates pessoais (que são também epistemológicos) próprios às idealizadoras.

Para seguir com o empreendimento foi preciso mobilizar um grupo. Como sócios fundadores, encontramos:

Arlinda Rocha Nogueira (IEB); Heloísa Belloto (IEB); José Eduardo Marques Mauro (IEB); Luci M. Hutter (IEB); Rosemarie E. Horch (IEB); Myriam Ellis (USP, IEB e Museu da Casa Brasileira); José Sebastião Witter

\footnotetext{
${ }_{20}$ Em 1981, Canabrava, Presidente da ANPUH, publicou um texto com um duplo objetivo: lançar a Revista Brasileira de História, que seria vinculada à associação, e fazer um balanço da trajetória da ANPUH. Nele, apesar de reconhecer a contribuição dos autodidatas, integrantes dos institutos históricos e geográficos, ela claramente os relacionava a um tipo de casta superior, as elites. Segundo Canabrava, a ANPUH vinha mudar esse quadro e assim inibia o amadorismo (CANABRAVA 1981, p. 4).

${ }_{21}$ Questionado sobre essa imagem, Estevão de Rezende Martins, sócio fundador da SBPH, testemunhou: "Essa imagem é a imagem clássica que foi dada na época, como forma de justificar a razoabilidade de criar a $\mathrm{SBPH}$, e na realidade a ANPUH, no período do regime militar que se estendeu até 1985, e mesmo as associações científicas como a SBPC ou associações profissionais como a OAB, adquiriram um viés sindical sim. E adquiriram um viés político partidário também. Certas pessoas entenderam que isso era um desvirtuamento das finalidades, dentre as quais as principais inspiradoras e fundadoras da SBPH, Cecília, Altiva e Maria Beatriz. Eu entendia de uma forma um pouco mais...liberal, e dada as circunstâncias políticas do país, essa partidarização e essa sindicalização, que não poderiam ser permanentes, eram pelo menos compreensíveis. Mas haviam os que consideravam que o viés de esquerda ou revolucionário era absolutamente intolerável, e por conseguinte, numa espécie de ilusão sobre a neutralidade metódica da ciência de uma herança truncada de Max Weber, achavam que uma sociedade que reunisse só pesquisadores estaria imune a essa partidarização, a essa sindicalização" (MARTINS 2016).
} 
(Arquivo do Estado de São Paulo); Odilon Nogueira de Matos (Academia Paulista de História, PUC Campinas); Célio Debes (Academia Paulista de História; IHGSP); Lycurgo dos Santos Filho (IHGSP); Maria Beatriz Nizza da Silva (USP); Aida M. Lavalle (UEPG); Olympio Westphalen (UEL); Altiva Balhana (UFPR); Cecília Westphalen (UFPR); Márcia Graf (UFPR); Odah G. Costa (UFPR); Oksana Boruszenko (UFPR); Arno Wehling (IHGB, UFRJ e Universidade Gama Filho); Darcy Damasceno (Biblioteca Nacional); Francisco de Assis Barbosa (Fundação Casa Rui Barbosa); Consuelo Pondé de Sena (UFBA); José Calans Brandão da Silva (UFBA); Renato Berbet de Castro (Conselho Estadual de Cultura da Bahia); Norma Goes Monteiro (UFMG); Mitiko O. Kehdy (UFMG); Earle Diniz Macarthy Moreira (UFRGS); Estevão C. de Rezende Martins (UnB); Maria Augusta Sant'Ana de Moraes (UFG); Walter Piazza (UFSC) (BOLETIM INFORMATIVO No 1 out. 1981).

Como haviam planejado, a sociedade abrangeria diferentes instituições e de diversas regiões do país. Tática para facilitar a divulgação e a mobilidade das reuniões, pois os encontros eram itinerantes e aconteciam anualmente, e configuração de outro elemento distintivo: alcançar núcleos de pesquisa desvinculados da docência universitária. A I Reunião Anual ocorreu em São Paulo, no Museu da Casa Brasileira, em 1981, ano de sua fundação. Como a primeira, todas as demais reuniões aconteceriam "fora" da universidade, acentuando seu caráter de zona neutra.

A SBPH não estabelecia temas para nortear as sessões de comunicação, a intenção era diagnosticar as linhas de pesquisa em curso. A forma de organização mantinha relativa estabilidade: duas ou três mesas-redondas, duas ou quatro conferências, comunicações divididas em grandes áreas (História Geral, História da América, História do Brasil, História Regional, Arquivos e Fontes, Metodologia e, às vezes, Historiografia) e, não assiduamente, painéis temáticos, geralmente relacionados aos centros de documentação.

As mesas-redondas assumiam papel central; refletiam o esforço de Westphalen e Nizza da Silva em mapear áreas de interesse da produção nacional para indicar suas lacunas e deficiências, em colocar em debate territórios de investigação com suas fontes, metodologias e técnicas e trazer à sociedade as datas comemorativas.

Já as conferências apresentam uma particularidade interessante. Das 64 , somente 21 foram proferidas por brasileiros (11 foram de Nizza da Silva). Embora a procedência tenha sido variada, 22 havia um diálogo acentuado com franceses, norte-americanos e portugueses. O internacionalismo foi outra marca de distinção da SBPH e está relacionado à movimentação da rede de

\footnotetext{
22 Miriam H. Pereira (Universidade de Lisboa), Alain Bideau (Universidade Lumière Lyon 2), Charles-Oliver Carbonell (Comissão Internacional de História da Historiografia), Ronald Hubscher (Universidade de Amiens), Adeline Daumard (Universidade Paris I), Jörn Rüsen (Universidade de Bochum), Jürgen Kocka (Universidade de Bielefeld), Peter Burke (Universidade de Cambridge), David Higgs (Universidade de Toronto), Muriel Nazzari (Universidade de Indiana), Manuel Pinto dos Santos (Universidade Nova de Lisboa), Elizabeth Kuznesof (Universidade do Kansas), Arthur Imhof (Universidade Livre de Berlim), Jorge Couto (Universidade de Lisboa), Karl Acham (Universidade de Graz), Avella Nello Angelo (Universidade de L'Aquila), Marianne Wiesebron (Universidade de Leiden); Ângela Domingues (Instituto de Investigação Científica Tropical/Lisboa), Avelino de Freitas de Menezes (Universidade dos Açores), Jean-Pierre Blay (Universidade de Paris I), Mary Karasch (Universidade de Oakland), Modj-ta-ba Chuo (Universidade de Tóquio), Alida Metcalf (Universidade de Trinity), Olivier Zeller (Universidade de Lumière Lyon II), Bourbacar Barry (Universidade de Dakar), Bert Barickman (Universidade do Arizona).
} 
sociabilidade de Nizza da Silva e Westphalen e a abertura historiográfica que desejaram conferir à SBPH. Orientação presente também na Revista da SBPH, lançada em 1983. ${ }^{23}$

Quanto à produção intelectual de Westphalen, observamos algumas experimentações e o desenvolvimento de uma visão cataclísmica sobre o ensino universitário e o direcionamento da pesquisa. O que estamos nomeando como experimentações são temáticas que não se originaram dos projetos propostos na UFPR a partir de 1959. Assim, surgiram textos de análises historiográficas, pesquisas sobre a atuação da juventude brasileira nos movimentos da Abolição e da proclamação da República; sobre ideias positivistas e movimentos sóciopolíticos brasileiros do final do século XIX e início do XX; sobre a repercussão da Revolução Francesa no Paraná; sobre a imagem da França que a imprensa paranaense recortou na figura do general De Gaulle durante 1940-1944; sobre níveis de riqueza de grupos de elite, constituição e transmissão de patrimônio, e seus modos de vida (lazeres e festas); e sobre modernidade e urbanização.

A perspectiva temporal das pesquisas foi uma de suas inquietações. Westphalen, assim como Nizza da Silva, vinha se manifestando sobre o "excessivo interesse pela história imediata" entre os alunos de pós-graduação. Não se trata de uma militância contra esse direcionamento (ela mesma trabalhou com recortes recentes), mas sim de detecção, segundo ela, do abandono do trabalho árduo com os arquivos e da crítica histórica em benefício de conclusões precipitadas e de "sabor jornalístico" (WESTPHALEN 1991). Esta avaliação pessimista 146 relaciona-se com a dita inconsistência do ensino de História Geral (Antiga, Medieval, Moderna e Contemporânea), com a concentração das pesquisas no Brasil republicano, e a formação de alunos deficientes em cultura geral. ${ }^{24}$

Havia uma proliferada desconfiança quanto à acentuada preocupação sociológica como motor das escolhas de temáticas de pesquisa, aliada a um engajamento desejoso de promover efeitos rápidos a partir da interpretação imediata dos fatos (NIZZA DA SILVA 1984, p. 208).

Na entrada do III Milênio, ${ }^{25}$ um quadro obscuro foi pintado por Westphalen no caminhar de sua velhice e o seu principal espaço de manifestação foi a SBPH, lugar onde permaneceu como Presidente até 1999. Ela sucedeu Nizza da Silva em 1990, devido a sua partida para Portugal. Com o agravamento de seus problemas de saúde e o estado crítico de Alzheimer de Balhana, à qual direcionava seus cuidados, o ritmo de suas atividades foi diminuindo e o bastão foi passado para Márcia Graf, sua ex-aluna que se doutorou na USP sob orientação de Nizza da Silva. E, ao que tudo indica, após o seu falecimento a sociedade não se manteve por longo tempo, e, em torno de 2005 e 2008 ela findou.

\footnotetext{
${ }^{23}$ Conforme o acervo disponível no Arquivo Público do Paraná, a revista parece ter sido editada até 2002, totalizando 23 números. Em todos, a Comissão Editorial contou com colaboradores estrangeiros. A revista também foi o lugar onde circulou a produção dos sócios correspondentes (estrangeiros), seja pela publicação de artigos, seja por resenhas das obras que enviavam à SBPH.

${ }^{24}$ Cecília Westphalen organizou na XI Reunião, em 1991, a mesa-redonda "Situação da pesquisa em História Geral" que contou com a participação de Pedro Paulo Abreu Funari (UNESP), Maria Sonsoles Guerras (UFRJ) e Sandra Brancato (PUC/RS).

${ }^{25}$ A tríade "História, historiador e III Milênio" foi tema de duas mesas-redondas, em 1997 e 1999. Alguns textos foram publicados nos números 13 e 16 da Revista da SBPH.
} 


\section{Considerações finais}

Maneiras de se fazer história e de se dizer historiador estão em constante negociação no campo historiográfico. Westphalen construiu seu modo de ser historiadora filiando-se a um tipo de prática específica, a história econômica e social quantitativa à la Annales. Formando redes de estudos em diferentes lugares de produção do discurso histórico, UFPR, EPHE, ANPUH e SBPH, divulgou e militou por essa forma de fazer história. Compreendendo-a como científica e livre de ideologias políticas; esse tipo de prática seria capaz de consolidar o status acadêmico da pesquisa histórica no Brasil.

Em 1998, a historiadora, aposentada da universidade e com o enfraquecimento interno de sua figura pelos novos grupos que se formavam no DEHIS, fora do maior espaço de circulação acadêmica, a ANPUH, e tendo como principal reduto a SBPH, com poder de alcance mais reduzido, publicou Porto de Paranaguá, um sedutor, a materialização do seu processo de aprendizagem da prática. Passados dois anos, relançou, com tímida revisão, a sua abandonada tese de cátedra sobre Carlos V.

O mesmo campo historiográfico que admitia, no final do século $X X$, a valorização da ação e a subjetividade dos indivíduos, parecia reticente à análise ancorada na história econômica quantitativa, desenvolvida com a potencialidade dos softwares e com pose de objetiva. Com o progressivo desamor ao quantitativo, a obra, que simboliza uma vida dedicada ao estudo do porto e suas flutuações econômicas, não obteve a almejada receptividade, a despeito do esforço em aproximar-se dos homens e do entendimento da história marítima brasileira. Contribuição, talvez, um pouco tardia, algo como uma obra "fora de lugar" em meio aos outros tipos de escrita da história que então dominavam.

\section{Referências bibliográficas}

ATA da Reunião de Fundação da Sociedade Brasileira de Pesquisa Histórica, realizada em 11 de agosto de 1981. Coleção Cecília Westphalen. Arquivo Público do Paraná, caixa sem identificação.

BERTIN, Jacques. A neográfia e o tratamento gráfico da informação. Curitiba: UFPR, 1986.

BOLETIM INFORMATIVO No. 1. São Paulo: SBPH, out. 1981. Coleção Cecília Westphalen. Arquivo Público do Paraná.

BOURDIEU, Pierre. As condições sociais da circulação internacional das idéias.

Enfoques, v. 1, n. 1, p. IV-XV, 2002.

BRAUDEL, Fernand. Escritos sobre a História. São Paulo: Perspectiva, 2009.

CANABRAVA, Alice P. A Associação Nacional dos Professores Universitários de História. Revista Brasileira de História, v. 1, n. 1, p. 1-11, 1981.

CERTEAU, Michel de. A escrita da história. Rio de Janeiro: Forense, 2002. 
DOSSE, François. O traje novo do presidente Braudel. In: LOPES, M. A. (Org.). Fernand Braudel: tempo e história. Rio de Janeiro: FGV, 2003, p. 34-55. FURET, François. A oficina da história. Lisboa: Gradiva, [1986].

; DAUMARD, Adeline. Méthodes de I'Histoire sociale: les Archives Notariales et la Mécanographie. In: Annales. Économies, Sociétés, Civilisations, ano 14, n. 4, p. 676-693, 1959.

GUIMARÃES, Manoel L. S. Historiografia e cultura histórica: notas para um debate. Ágora, v. 11. n. 1, p. 31-47, 2005.

HARTOG, François. O século XIX e a história: o caso Fustel de Coulanges. Rio de Janeiro: Ed. UFRJ, 2003.

HENRY, Louis. Técnicas de Análise em Demografia Histórica. Tradução Altiva Pilatti Balhana e Jayme Antônio Cardoso. Curitiba: Ed. UFPR, 1977.

INFORMATIONS BIBLIOGRAPHIQUES. Revue française de science politique, [S.I.], ano 8, n. 4, p. 982, 1958.

LAPA, José R. do Amaral. Carta a Cecília Westphalen. Marília, 11 mai. 1965. Coleção Cecília Westphalen. Arquivo Público do Paraná, caixa sem identificação.

LORIGA, Sabina. O pequeno x: da biografia à história. Belo Horizonte: Autêntica, 2011.

148 MACHADO, Daiane V. "Pas de chiffres, pas d'histoire:" a construção do Programa de Pós-Graduação em História do Brasil da UFPR. In: PRIORI, Angelo (Org.). História do Paraná: novos caminhos e novas abordagens. Curitiba: CRV, 2016b, p. 235-255.

. Por uma "ciência histórica": o percurso intelectual de Cecília Westphalen, 1950-1998. Tese (Doutorado em História) - Programa de Pós-Graduação em História, Universidade Estadual Paulista, Assis, 2016a.

MARCHI, Euclides. et al. Trinta anos de historiografia: um exercício de avaliação.

Revista Brasileira de História, v. 13, n. 25/26, p. 133-141, 1992/1993.

. Relendo nossos mestres. Ciências Humanas, n. 4, p. 37-53, 1995.

MARTINS, Estevão C. de R. Estevão Chaves de Rezende Martins: depoimento [abr. 2016]. Entrevistadora: Daiane Machado. Skype, 2016.

MOÇÃO No 5. SIMPÓSIO DE PROFESSORES UNIVERSITÁRIOS DE HISTÓRIA ANPUH, IX, 1977, Florianópolis. Anais... São Paulo: Faculdade de Filosofia Ciências e Letras da USP, 1979, p. 117-118. 1v.

MOÇÃO No 7. SIMPÓSIO DE PROFESSORES UNIVERSITÁRIOS DE HISTÓRIA ANPUH, IX, 1977, Florianópolis. Anais... São Paulo: Faculdade de Filosofia Ciências e Letras da USP, 1979, p. 121. 1v.

MOTTA, Rodrigo P. S. As universidades e o regime militar: cultura política brasileira e modernização autoritária. Rio de Janeiro: Zahar, 2014. 
NAPOLITANO, Marcos. 1964. História do Regime Militar Brasileiro. São Paulo: Contexto, 2014.

NIZZA DA SILVA, Maria B. (Org.). Teoria da História. São Paulo: Cultrix, 1976. . Carta a Cecília Westphalen. São Paulo, 8 mar. 1978. Coleção Cecília Westphalen. Arquivo Público do Paraná, caixa 3.

. Rumos da pesquisa histórica no Brasil. In: SOCIEDADE BRASILEIRA DE PESQUISA HISTÓRIA (SBPH), III, 1983, Brasília. Anais... São Paulo: SBPH, 1984, p. 207-210.

NOIRIEL, Gérard. Sur la "crise" de I’histoire. Paris: Gallimard, 2005.

RAMOS, Igor G. Genealogia de uma operação historiográfica: Edward Palmer Thompson, Michel Foucault e os historiadores brasileiros da década de 1980. São Paulo: Cultura Acadêmica, 2015.

RICHARD, Jean. Un 'Charles-Quint' Brésilien. Annales de Bourgogne, p. 223$224,1958$.

ROBERT, Ricard. Cecília María Westphalen, Carlos-Quinto 1500-1558, seu Império universal. Bulletin Hispanique, v. 60, n. 4, p. 564-565, 1958.

SILVA, Helenice R. da. Fragmentos da história intelectual: Entre questionamentos e perspectivas. Campinas: Papirus, 2002.

ROIZ, Diogo da S. Os caminhos (da escrita) da história e os descaminhos de seu ensino: a institucionalização do ensino universitário de História na Faculdade de Filosofia, Ciências e Letras da Universidade de São Paulo (1934-1968). Curitiba: Appris, 2012.

SIMÕES DE PAULA, Maria R. da C. R. Introdução. SIMPÓSIO DE PROFESSÔRES UNIVERSITÁRIOS DE HISTÓRIA - APUH, VI, 1971, Goiânia. Anais... São Paulo: Faculdade de Filosofia Ciências e Letras da USP, 1973, p. 7-25.

. IX Simpósio de História, mudanças estruturais (Florianópolis, 1977). In: SIMPÓSIO DE PROFESSORES UNIVERSITÁRIOS DE HISTÓRIA ANPUH, IX, 1977, Florianópolis. Anais... São Paulo: Faculdade de Filosofia Ciências e Letras da USP, 1979, p. 13-32.

SIRINELLI, Jean-François. As elites culturais. In: RIOUX, Jean-Pierre;

(Dir.). Para uma história cultural. Lisboa: Estampa, 1998, p. 259-279.

. Os intelectuais. In: RÉMOND, Réne. Por uma história política. Rio de Janeiro: UFRJ; FGV, 2003, p. 231-269.

VIANA, Iêda. A intervenção de intelectuais na reforma educacional do governo militar: discursos e práticas nas escolas municipais de Curitiba. Antítese, v. 8, n. 15, p. $243-268,2015$.

WESTPHALEN, Cecília. $1^{\text {a }}$ CIRCULAR SBPH. Curitiba, 11 nov. 1980. Coleção Cecília Westphalen. Arquivo Público do Paraná, caixa sem identificação. 
Carlos-Quinto, 1500/1558: seu Império universal. Tese (Doutorado em História) - Universidade Federal do Paraná, Curitiba, 1955.

- Carta a Altiva Pilatti Balhana. Colônia, 29 nov. 1958. Coleção Cecília Westphalen. Arquivo Público do Paraná, caixa sem identificação.

- Carta a Altiva Pilatti Balhana. Paris, 7 abr. 1970. Coleção Cecília Westphalen. Arquivo Público do Paraná, caixa sem identificação.

- Carta a Altiva Pilatti Balhana. Paris, 21 abr. 1970. Coleção Cecília Westphalen. Arquivo Público do Paraná, caixa sem identificação.

- Carta a Altiva Pilatti Balhana. Paris, 24 jun. 1970. Coleção Cecília Westphalen. Arquivo Público do Paraná, caixa sem identificação.

. Carta a Fernand Braudel. Curitiba, 1 out. 1962. Coleção Fernand Braudel. Institut de France.

. Carta a Fernand Braudel. Curitiba, 3 dez. 1963. Coleção Fernand Braudel. Institut de France.

- Carta a Fernand Braudel. Curitiba, 5 mai. 1964. Coleção Cecília Westphalen. Arquivo Público do Paraná, caixa sem identificação.

- Carta a Jayme A. Cardoso. Curitiba, 29 ago. 1977. Coleção Cecília Westphalen. Arquivo Público do Paraná, caixa sem identificação.

- Carta a José Roberto do Amaral Lapa. Curitiba, 25 mai. 1965. Coleção 150 Cecília Westphalen. Arquivo Público do Paraná, caixa sem identificação.

- Carta a Maria Beatriz Nizza da Silva. Curitiba, [ago] 1980. Coleção Cecília Westphalen. Arquivo Público do Paraná, caixa sem identificação.

- Carta a Mba de Ferrante. Boletim do Arquivo Estadual do Paraná, Curitiba, n. 17, p. 33-42, 1985.

- Carta a Sergio O. Nadalin. Curitiba, 9 ago. 1977. Coleção Cecília Westphalen. Arquivo Público do Paraná, caixa não identificada.

et al. Ata da reunião do Departamento de História da Faculdade de Filosofia da Universidade do Paraná, realizada em 2 de dezembro de 1964 [registrando sua constituição em princípios de maio de 1959]. História -

Questões \& Debates, n. 50, p. 285-315, 2009.

et al. Estudos Sociais a partir da Longa Duração. Curitiba: Ed. UFPR, 1976.

et al. Estudos Sociais a partir da Longa Duração. Relatório no 3. Curitiba: UFPR, 1977.

- História e Contemporaneidade. In: SOCIEDADE BRASILEIRA DE PESQUISA HISTÓRIA (SBPH), X, 1990, Curitiba. Anais... Curitiba: SBPH, 1991, p. 59-60.

. O Pôrto de Paranaguá no ano de 1826. Estudo de micro-conjuntura.

Boletim da Universidade do Paraná, Departamento de História, 
Curitiba, n. 2, dez. 1962.

Pequena História do Paraná. São Paulo: Melhoramentos, 1953.

. Porto de Paranaguá, um sedutor. Curitiba: Secretaria de Estado da Cultura, 1998.

WILLE, José. Memória paranaense: entrevista com Cecília Westphalen. Curitiba: Nossa Cultura, 2010, v. 6. 